\title{
Comparative genomics and transcriptomics of host-pathogen interactions in insects: evolutionary insights and future directions
}

\section{Citation}

Sackton, Timothy B. "Comparative Genomics and Transcriptomics of Host-pathogen Interactions in Insects: Evolutionary Insights and Future Directions." Current Opinion in Insect Science 31 (2018): 106-113.

\section{Permanent link}

http://nrs.harvard.edu/urn-3:HUL.InstRepos:42656562

\section{Terms of Use}

This article was downloaded from Harvard University's DASH repository, and is made available under the terms and conditions applicable to Open Access Policy Articles, as set forth at http:// nrs.harvard.edu/urn-3:HUL.InstRepos:dash.current.terms-of-use\#OAP

\section{Share Your Story}

The Harvard community has made this article openly available. Please share how this access benefits you. Submit a story. 


\title{
Comparative genomics and transcriptomics of host-pathogen interactions in insects:
} evolutionary insights and future directions

Timothy B. Sackton

Informatics Group, Faculty of Arts and Sciences, Harvard University, Cambridge, MA 02138

Email: tsackton@g.harvard.edu

\begin{abstract}
Classical evolutionary studies of protein-coding genes have established that genes in the canonical immune system are often among the most rapidly evolving within and between species. As more genomes and transcriptomes across insects are sequenced, it is becoming clear that duplications and losses of immune genes are also a likely consequence of hostpathogen interactions. Furthermore, particular species respond to diverse pathogenic challenges with a wide range of challenge-specific responses that are still poorly understood. Transcriptional studies, using RNA-seq to characterize the infection-regulated transcriptome of diverse insects, are crucial for additional progress in understanding the ecology and evolution of the full complexity of the host response.
\end{abstract}

\section{Highlights}

- Expansions and losses of immune genes are an important component of evolutionary change across species

- Transcriptional response to infection involves diverse processes beyond canonical immune pathways 
- Careful RNA-seq studies across multiple species are needed to understand how inducible responses evolve

\section{Introduction}

Genes involved in immune defense have long been recognized as hotspots for rapid evolution in many organisms including insects $[1,2]$. In Drosophila, early population genetic $[3,4]$ and comparative genomic $[5,6]$ studies demonstrated that key components of the innate immune system experienced substantially more adaptive protein evolution than typical genes in the genome. More recently, a combination of functional and comparative analysis showed a probable role for balancing selection in the maintenance of sequence diversity in antimicrobial peptides in Drosophila $[7,8]$. While Drosophila has received the most research attention, evidence for positive selection in insect immune genes is common in other groups as well [911]. These studies have established rapid, adaptively driven sequence evolution of immune proteins as a fundamental tenet of insect immunity $[12,13]$.

Over the past decade, increasing evidence has accumulated that adaptive changes in protein sequence are far from the only important evolutionary dynamics occurring in insect immune systems. Comparisons of gene content in the immune system between different insect orders [14-16], distantly related dipterans [17] and more closely related drosophilids [6] all suggest substantial gains (often via gene duplication) and losses of immune system genes, especially outside signaling pathways. While determining the functional impact of these changes is not easy, transcriptomics provides a way forward, especially in non-model taxa where genetic tools are not readily accessible [18].

Transcriptional studies have been particularly important for understanding the full complexity of the insect immune response. The canonical innate immune system of insects consists of a set of receptor molecules that detect infection (usually via pathogen-associated or danger-associated molecular patterns) and trigger (generally) conserved signaling cascades (in particular Toll, imd, JAK/STAT, and JNK pathways) that ultimately serve to control the 
transcription of a variety of downstream effectors [19]. Early microarray studies in Drosophila melanogaster [20-23] were crucial in establishing this picture of insect immunity, although as discussed below recent evidence suggests this may be substantially incomplete. Most early transcriptome studies were limited to model systems, due in large part to the requirement that microarrays need to be designed based on known transcript sequences. With the advent of RNA-sequencing, this limitation was removed, and in the past several years transcriptional studies of non-model insects have become extremely common [18] (Supplemental Table 1).

In this review, I discuss several insights into insect immunity that have been facilitated by transcriptional and genomic studies, focusing on their evolutionary implications. First, I will review recent work on the evolutionary dynamics of immune systems beyond sequence evolution, focusing on gene duplication, gene loss, rewiring of signaling pathways, and changes in the transcriptional response to infection. While this area of study is still in its infancy, increasingly affordable sequencing is poised to make these studies widespread. Second, I review the role of transcriptome studies in revising our understanding of the complexity of the transcriptional response to infection, both within and between species. Infection results in differential regulation of a wide array of pathways outside canonical immune genes, a process that RNA-seq studies have made abundantly clear, although whether these represent novel mechanisms of tolerance or resistance, or physiological consequences of infection with little or no benefit to the host, remains an open question in most cases. Taken together, these lines of research suggest that we are still far from understanding the entire process of how immune systems evolve and function.

\section{Beyond protein evolution: evolutionary dynamics of gene content in insect immune systems}

While most studies of rapid evolution in insect immune genes have focused on identifying adaptive changes in protein sequence, changes in copy number and/or gene content (e.g., via gene duplication, gene loss, or de novo gene origination) are often of selective importance $[24,25]$ and can be associated with functionally important traits in insects $[26,27]$. Early comparative genomic studies in holometabolous insects pointed to deep conservation of 
canonical signaling components (the Toll, Imd, JAK/STAT, and JNK signal transduction pathways), while also suggesting that upstream recognition and downstream effector genes may be more likely to change copy number or experience species-specific expansion $[6,14,17,28]$. In recent years, dramatic increases in the number of sequenced insect genomes, as well as increasing feasibility of direct measures of infection-regulated genes using RNA-seq, have added substantial new details to this picture.

Depauperate immune systems in insects?

Insects have a diverse array of life histories and ecologies, including some that have been proposed to be associated with reduced investment in individual immune defense. Most prominently, social insects engage in a variety of behaviors to reduce the spread of infection in colonies, such as removal of infected individuals from colonies ("social immunity", [29]). Other insects, such as aphids, have microbial symbionts that may provide defense against pathogens $[30,31]$. If these forms of immunity reduce the need for individual defense pathways, it is reasonable to hypothesize that, as a consequence, genes required for immune defense may be lost or pseudogenized. Indeed, the first genome-wide studies in honeybees [14] and pea aphids [16] showed evidence for reduced number of homologs of canonical immune genes, based on comparisons to genes annotated in Drosophila (Figure 1). The honeybee genome, while containing homologs of all major signaling pathways identified in Diptera, encodes far fewer copies of several families of recognition and effector genes [14]. The pea aphid genome is missing homologs for many components of the Imd signaling pathway, in addition to a dramatic reduction in effector gene family content and complete loss of peptidoglycan recognition proteins (PGRPs) and other recognition proteins [16].

Hymenoptera now have among the most sequenced genomes of any insect order [32], and additional genomes of both social and solitary species have revealed that a reduced complement of homologs of dipteran immune genes does not appear to be associated with sociality $[15,33,34]$ (Figure 1). Although many fewer termite genomes are available, similar lack of differentiation in immune gene content is apparent between termites on different extremes 
of sociality [35]; as more Blattodea genomes become available [36] these comparisons will have increasing power.

Comparisons that focus primarily on homologs of canonical immune genes first identified in dipterans may not represent the full picture of hymenopteran immunity. Transcriptome studies using RNA-seq to characterize genes regulated by infection showed that a substantial number of infection-regulated genes in the parasitic wasp Nasonia vitripennis [37], and in multiple ant species [38-40], do not have clearly identifiable homologs in dipterans. This suggests that the observation of reduced numbers of homologs of dipertan immune genes in bees and other hymenopterans may, in part, be an artifact of homology-based annotation and the evolutionary distance between Diptera and Hymenoptera. The de novo evolution of Hymenoptera-restricted immune genes, the recruitment of existing genes to have an immune role in Hymenoptera, or rapid sequence evolution hindering our ability to recognize homolog could all produce a reduced annotation in distant species. Any of these models are plausible, although extreme caution is warranted in interpreting lack of detectable homologs as prima facie evidence for de novo gene origination [41,42]. Recruitment of existing genes to a novel immune role has been shown to occur in tetrapods: recent comprehensive RNA-seq study of the interferon response across ten tetrapods (nine mammals plus chicken) revealed, in addition to a core set of conserved interferon-responsive genes, evidence for the evolution of new transcriptional responsiveness across the phylogeny [43].

In the pea aphid, genomic evidence suggesting the absence of the Imd signaling pathways and a number of recognition proteins, including a complete absence of PGRPs [16] is complemented by some functional genomic data. Early transcriptome studies using suppression subtractive hybridization and EST screens failed to identify induced antimicrobial peptides in pea aphids [44]; proteomic screens of hemolymph after artificial infection with E. coli also did not detect strong evidence for inducible antimicrobial peptides [16]. Furthermore, pea aphids do not appear to pay a physiological cost from exposure to natural bacterial pathogens, supporting a role for a limited immune response to bacteria [45].

Nonetheless, the sequencing of genomes and transcriptomes of a number of additional hemimetabolous insects and more diverged arthropods has revealed that absence of Imd 
pathway components, and reductions or absence of PGRPs, are not uncommon (Figure 1).

Indeed, few arthropods outside holometabolous insects appear to have a completely intact Imd pathway, and many are missing all transmembrane PGRPs or all PGRPs entirely [46-49].

Although the existing data does not definitively resolve whether the Imd pathway arose and acquired an immune function in the ancestor of holometabolous insects [46], or represents an older pathway independently lost in many lineages [47], it appears clear that large-scale reorganization in the identity of major immune pathways is be plausible across long evolutionary timescales. Ultimately, the combination of more complete genomic representation outside Holometabola and direct measures of infection-regulated transcription using RNA-seq in diverse insects will be required to fully understand the degree to which particular species truly have reduced repertoires of immune genes in their genomes.

\section{Expansion of innate immune genes}

In many cases, genomic and transcriptomic studies in insects have revealed evidence for expanded repertoires of immune genes, often through gene duplication and typically involving genes encoding recognition or effector proteins. The idea that host-pathogen arms races can drive copy number changes in critical genes of the immune system has a long history [50,51]. In insects, comparative genomic comparisons showed that effector genes in particular were prone to diversification across dipterans $[6,17]$. These observations support biochemical evidence for lineage-restricted antimicrobial peptides, including diapausin [52] and gambicin [53], although simple absence of homology can also be explained by rapid sequence evolution, especially in short proteins.

A particularly striking example of immune gene expansion is in the Harlequin ladybird Harmonia axyridis, a species native to central and eastern Asia that has become highly invasive in many regions, to the point of displacing native ladybird competitors. A de novo transcriptome assembly of $H$. axyridis after infection with several immune elicitors identified more than 50 putative antimicrobial peptides, a very large number for any insect [54]. Comparative transcriptomics with close relatives further showed that many of these AMPs are specifically 
expanded in $H$. axyridis [55]. Functional studies have shown that $H$. axyridis has a more potent antimicrobial defense response than the native Coccinella septempunctata [56], and it is resistant to a parasitic microsporidian that is lethal to native competitors $[55,57]$. While transgenic manipulations to test the role of the expanded immune repertoire directly have not been possible in ladybirds, comparative evidence is strongly suggestive that the observed immune gene expansions are functionally related to improved defense against pathogens and parasites, potentially facilitating the invasive potential of $H$. axyridis [55,57] (but see [58]).

Gene duplications and immune gene family expansions have also proposed to arise as a consequence of insect ecology, particularly in response to high pathogen burdens. Increased copy number can both increase the speed of humoral immune response and facilitate functional diversification, albeit potentially increasing autoimmune or other costs of resistance. A transcriptome study using EST sequencing in drone fly maggots, which live in highly septic, contaminated water, showed a particularly high diversity of AMP transcripts [59]. This led the authors to hypothesize that environments particularly rich in bacteria may lead to selection for increased diversity of immune components. More recently, both genomic and RNA-seq studies from Musca domestica -- an insect that also inhabits particularly septic environments both as larvae and adults -- revealed unusually large expansions of certain immune gene families, including the thioester-containing proteins and the cecropin AMP family [60,61] (Figure 1). Further work characterizing immune gene family evolution in more species with diverse ecologies and associated bacterial communities will continue to refine this hypothesis.

\section{Complexity of the transcriptional response to infection}

The advent of RNA-sequencing technology more than a decade ago has had a major impact on the study of insect immunity, with over 75 studies looking for differential gene expression after an infectious challenge published to date (Supplemental Table 1). In general, this wide range of studies has focused on annotating immune pathways in species (often of agriculture importance) without high quality genomes (e.g., [62,63]), elucidation of hostpathogen interactions of ecological interest (e.g., [38,64-66]), and characterization of 
pathogen-vector interactions of medical relevance (e.g., $[67,68])$. There has been relatively less focus on explicitly comparative studies, either comparing multiple pathogens in the same species, or comparative studies across species, albeit with a few exceptions (e.g., [38,55,6974]).

The degree to which the transcriptional response to infection varies across different pathogenic challenges in the same species is a critical question for understanding hostpathogen interactions in an ecological and evolutionary context. Two key recent studies - in $D$. melanogaster [70] and in A. mellifera [75] - have tackled this question in detail. While a number of microarray and RNA-seq studies have been done in D. melanogaster (e.g., [20,23]), previous work has typically focused on one or a few model bacteria, often non-pathogenic. To overcome this limitation, Troha and colleagues [70] infected D. melanogaster with ten different bacterial species across a range of pathogenicity, including several bacterial strains that have been recovered from wild fruit flies, and used RNA-seq to measure the transcriptional response to infection. They showed that, while a core of canonical immune genes are induced in most conditions, a substantial number of consistently regulated genes were involved in cellular and metabolic homeostasis, some of which may have functions related to immune tolerance [76], while others may reflect physiological consequences of infection. Furthermore, the majority of genes regulated in any particular infection were not part of the core, universally regulated response, implying a high degree of host-pathogen specificity in the transcriptional response to infection, largely outside the well understood immune pathways.

In honeybees, Doublet and colleagues [75] re-analyzed published microarray and RNAseq studies examining the transcriptional response to infection with a variety of different pathogens. This work identified many similar patterns, albeit with reduced power and precision due to the need to rely on a heterogeneous collection of previously published studies varying in quality, as opposed to generating a consistent new dataset as in [70]. Despite these limitations this work also revealed both a core set of commonly regulated genes, including upregulation of canonical immune pathways and downregulation of metabolic genes, and a set of pathogen restricted genes enriched for functions like apoptosis. 
Similar results have been seen in previous studies, including comparisons of different viral infections in Aedes mosquitos [72,73,77], comparisons of diverse pathogenic challenges in Culex mosquitoes [78], and comparisons between different fungal pathogens in ants [38]. Taken together, these studies imply that the canonical immune response is only a small part of the full suite of transcriptional changes associated with infection, and furthermore that a substantial fraction of the insect response to infection is highly specific to particular host-pathogen (or host-microbe) interactions. Importantly, it remains an open question the extent to which the broad transcriptional response to infection outside canonical immune pathways represents novel mechanisms of tolerance or resistance. Infection is likely to perturb a number of cellular and physiological processes, and much of the wider transcriptional response may reflect instead the physiological burden of disease. Ultimately, additional functional work (e.g., gene knockouts as in [70]) will be required to conclusively establish the role of genes transcriptionally regulated by infection.

While transcriptomic studies are increasingly using ecologically relevant pathogens, less attention has focused on comparative studies across species. Theoretical and computational advances in explicitly phylogenetic approaches for modeling gene expression data [79-81] are maturing and offer important benefits over pairwise tests, which can be misleading [82]. While incorporating ecologically relevant infectious challenges into comparative work will lead to better understanding of the full degree of evolutionary divergence in infection-regulated gene expression, these studies will also pose an experimental design challenge to keep costs and sample sizes manageable. Previous work has often used few or no biological replicates, potentially to increase experimental design complexity while minimizing costs, but this severely reduces both power and reproducibility $[83,84]$. Lack of adequate reference genomes also poses a challenge to comparative work, as methods for de novo transcriptome assembly often produce highly fragmented and duplicated reference transcriptomes that perform poorly for differential expression analysis in the absence of significant post-processing [85]. Fortunately, initiatives such as the i5K project [86] and declining sequencing costs are rapidly increasing the number of assembled insect genomes available, and new approaches such as Tag-seq [87], in 
which only a short tag for each gene is sequenced, are making large-scale sequencing experiments including adequate replication increasingly feasible.

\section{Conclusions}

Both genomic and transcriptomic studies have contributed substantially to our understanding of how insect immune systems evolve. Over the past decade, these studies have shown that, while adaptive evolution of protein sequence in canonical immune genes are clearly important, changes in gene content at short and long time scales, as well as transcriptional responses outside canonical pathways, are also significant components of the eco-evolutionary dynamics of host-pathogen interactions. Insects, with a rapidly expanding number of sequenced genomes and a vast arrange of host ecologies and life histories, will continue to provide new insights into host-pathogen evolutionary dynamics.

\section{Acknowledgments}

I'd like to thank Rob Unckless, Erik Dopman, Rich Meisel, Seth Barribeau, and two anonymous reviewers for helpful comments and discussion.

\section{Figure Legends}

\section{Figure 1. Summary of changes in gene content across insect immune systems.}

Cladogram of major insect genera with characterized immune systems (topology following [88]). Status of major signaling pathways is indicated in the far right column: dark purple = complete, with paler shades proportional to the number of missing genes. Clades missing the Imd gene are marked with a red " $X$ ". Counts of key effector and recognition gene families are shown for a subset of species. Blocks are colored orange/red if counts are higher than typical and blue if lower than typical; gray indicates not analyzed. Data are summarized from $[15,16,46,47,61]$. All silhouettes from phylopic.org. 


\section{References}

1. Hughes AL, Nei M: Pattern of nucleotide substitution at major histocompatibility complex class I loci reveals overdominant selection. Nature 1988, 335:167-170.

2. Kosiol C, Vinar T, da Fonseca RR, Hubisz MJ, Bustamante CD, Nielsen R, Siepel A: Patterns of positive selection in six Mammalian genomes. PLoS Genet 2008, 4:e1000144-17.

3. Schlenke TA, Begun DJ: Natural selection drives Drosophila immune system evolution. Genetics 2003, 164:1471-1480.

4. Obbard DJ, Welch JJ, Kim K-W, Jiggins FM: Quantifying Adaptive Evolution in the Drosophila Immune System. PLoS Genet 2009, 5:e1000698-13.

5. Obbard DJ, Jiggins FM, Halligan DL, Little TJ: Natural selection drives extremely rapid evolution in antiviral RNAi genes. Curr Biol 2006, 16:580-585.

6. Sackton TB, Lazzaro BP, Schlenke TA, Evans JD, Hultmark D, Clark AG: Dynamic evolution of the innate immune system in Drosophila. Nature Publishing Group 2007, 39:1461-1468.

7. Chapman JR, Hill T, Unckless RL: Balancing selection drives maintenance of genetic variation in Drosophila antimicrobial peptides. bioRxiv 2018, doi:10.1101/298893.

8. Unckless RL, Howick VM, Lazzaro BP: Convergent Balancing Selection on an Antimicrobial Peptide in Drosophila. Curr Biol 2016,

- This study identifies evidence for balancing selection in an antimicrobial peptide using combination of functional and genomic evidence. This is one of the first demonstrations of likely balancing selection in insect immune genes.

9. Roux J, Privman E, Moretti S, Daub JT, Robinson-Rechavi M, Keller L: Patterns of Positive Selection in Seven Ant Genomes. Mol Biol Evol 2014, 31:1661-1685.

10. Viljakainen L, Evans JD, Hasselmann M, Rueppell O, Tingek S, Pamilo P: Rapid Evolution of Immune Proteins in Social Insects. Mol Biol Evol 2009, 26:1791-1801.

11. Bulmer MS, Crozier RH: Variation in positive selection in termite GNBPs and Relish. Mol Biol Evol 2006, 23:317-326.

12. Lazzaro BP: Natural selection on the Drosophila antimicrobial immune system. Curr Opin Microbiol 2008, 11:284-289.

13. Viljakainen L: Evolutionary genetics of insect innate immunity. Brief Funct Genomics 2015, 14:407412.

14. Evans JD, Aronstein K, Chen YP, Hetru C, Imler J-L, Jiang H, Kanost M, Thompson GJ, Zou Z, Hultmark $\mathrm{D}$ : Immune pathways and defence mechanisms in honey bees Apis mellifera. Insect Mol Biol 2006, 15:645-656. 
15. Barribeau SM, Sadd BM, du Plessis L, Brown MJF, Buechel SD, Cappelle K, Carolan JC, Christiaens O, Colgan TJ, Erler $\mathrm{S}$, et al.: A depauperate immune repertoire precedes evolution of sociality in bees. Genome Biol 2015, 16:83.

- This study reports an analysis of immune genes in primitively social and solitary bees, and was one of the first studies to show that a reduction in canonical immune genes is not associated with eusociality in bees.

16. Gerardo NM, Altincicek B, Anselme C, Atamian H, Barribeau SM, de Vos M, Duncan EJ, Evans JD, Gabaldón T, Ghanim M, et al.: Immunity and other defenses in pea aphids, Acyrthosiphon pisum. Genome Biol 2010, 11:R21-16.

17. Waterhouse RM, Kriventseva EV, Meister S, Xi Z, Alvarez KS, Bartholomay LC, Barillas-Mury C, Bian G, Blandin S, Christensen BM, et al.: Evolutionary Dynamics of Immune-Related Genes and Pathways in Disease-Vector Mosquitoes. Science 2007, 316:1738-1743.

18. Oppenheim SJ, Baker RH, Simon S, DeSalle R: We can't all be supermodels: the value of comparative transcriptomics to the study of non-model insects. Insect Mol Biol 2015, 24:139-154.

19. Buchon N, Silverman N, Cherry S: Immunity in Drosophila melanogaster--from microbial recognition to whole-organism physiology. Nat Rev Immunol 2014, 14:796-810.

20. De Gregorio E, Spellman PT, Rubin GM, Lemaitre B: Genome-wide analysis of the Drosophila immune response by using oligonucleotide microarrays. Proceedings of the National Academy of Sciences 2001, 98:12590-12595.

21. De Gregorio E, Spellman PT, Tzou P, Rubin GM, Lemaitre B: The Toll and Imd pathways are the major regulators of the immune response in Drosophila. EMBO J 2002, 21:2568-2579.

22. Boutros $M$, Agaisse $H$, Perrimon $N$ : Sequential activation of signaling pathways during innate immune responses in Drosophila. Dev Cell 2002, 3:711-722.

23. Irving P, Troxler L, Heuer TS, Belvin M, Kopczynski C, Reichhart JM, Hoffmann JA, Hetru C: A genome-wide analysis of immune responses in Drosophila. Proceedings of the National Academy of Sciences 2001, 98:15119-15124.

24. Emerson JJ, Cardoso-Moreira M, Borevitz JO, Long M: Natural selection shapes genome-wide patterns of copy-number polymorphism in Drosophila melanogaster. Science 2008, 320:16291631.

25. Cardoso Moreira M, Arguello JR, Gottipati S, Harshman LG, Grenier JK, Clark AG: Evidence for the fixation of gene duplications by positive selection in Drosophila. Genome Res 2016, 26:787-798.

26. Zhao C, Escalante LN, Chen H, Benatti TR, Qu J, Chellapilla S, Waterhouse RM, Wheeler D, Andersson MN, Bao R, et al.: A Massive Expansion of Effector Genes Underlies Gall-Formation in the Wheat Pest Mayetiola destructor. Curr Biol 2015, 25:613-620.

27. Schmidt JM, Good RT, Appleton B, Sherrard J, Raymant GC, Bogwitz MR, Martin J, Daborn PJ, Goddard ME, Batterham P, et al.: Copy Number Variation and Transposable Elements Feature in 
Recent, Ongoing Adaptation at the Cyp6g1 Locus. PLoS Genet 2010, 6:e1000998.

28. Zou Z, Evans JD, Lu Z, Zhao P, Williams M, Sumathipala N, Hetru C, Hultmark D, Jiang H: Comparative genomic analysis of the Tribolium immune system. Genome Biol 2007, 8:R177.

29. Cremer S, Armitage SAO, Schmid-Hempel P: Social immunity. Curr Biol 2007, 17:R693-702.

30. Oliver KM, Smith AH, Russell JA: Defensive symbiosis in the real world - advancing ecological studies of heritable, protective bacteria in aphids and beyond. Funct Ecol 2014, 28:341-355.

31. Gerardo NM, Parker BJ: Mechanisms of symbiont-conferred protection against natural enemies: an ecological and evolutionary framework. Curr Opin Insect Sci 2014, 4:8-14.

32. Branstetter MG, Childers AK, Cox-Foster D, Hopper KR, Kapheim KM, Toth AL, Worley KC: Genomes of the Hymenoptera. Current Opinion in Insect Science 2018, 25:65-75.

33. Otani S, Bos N, Yek SH: Transitional Complexity of Social Insect Immunity. Frontiers in Ecology and Evolution 2016, 4:69.

34. Kapheim KM, Pan H, Li C, Salzberg SL, Puiu D, Magoc T, Robertson HM, Hudson ME, Venkat A, Fischman BJ, et al.: Genomic signatures of evolutionary transitions from solitary to group living. Science 2015, 348:1139-1143.

35. Korb J, Poulsen M, Hu H, Li C, Boomsma JJ, Zhang G, Liebig J: A genomic comparison of two termites with different social complexity. Front Genet 2015, 6:9.

36. Harrison MC, Jongepier E, Robertson HM, Arning N, Bitard-Feildel T, Chao H, Childers CP, Dinh H, Doddapaneni $\mathrm{H}$, Dugan $\mathrm{S}$, et al.: Hemimetabolous genomes reveal molecular basis of termite eusociality. bioRxiv 2017, doi:10.1101/181909.

37. Sackton TB, Werren JH, Clark AG: Characterizing the Infection-Induced Transcriptome of Nasonia vitripennis Reveals a Preponderance of Taxonomically-Restricted Immune Genes. PLoS One 2013, 8:e83984-11.

38. Yek SH, Boomsma JJ, Schiøtt M: Differential gene expression in Acromyrmex leaf-cutting ants after challenges with two fungal pathogens. Mol Ecol 2013, 22:2173-2187.

39. Gupta SK, Kupper M, Ratzka C, Feldhaar H, Vilcinskas A, Gross R, Dandekar T, Förster F: Scrutinizing the immune defence inventory of Camponotus floridanus applying total transcriptome sequencing. BMC Genomics 2015, 16:540.

40. Viljakainen L, Jurvansuu J, Holmberg I, Pamminger T, Erler S, Cremer S: Social environment affects the transcriptomic response to bacteria in ant queens. Ecol Evol 2018, 8:11031-11070.

41. McLysaght A, Hurst LD: Open questions in the study of de novo genes: what, how and why. Nat Rev Genet 2016, 17:567-578.

42. Casola C: From de novo to "de nono": most novel protein coding genes identified with phylostratigraphy represent old genes or recent duplicates. bioRxiv 2018, doi:10.1101/287193.

43. Shaw AE, Hughes J, Gu Q, Behdenna A, Singer JB, Dennis T, Orton RJ, Varela M, Gifford RJ, Wilson 
SJ, et al.: Fundamental properties of the mammalian innate immune system revealed by multispecies comparison of type I interferon responses. PLOS Biol 2017, 15:e2004086.

- This study is a clear demonstration of the value of comparing transcriptional responses to immune challenge across a phylogeny, albeit in vertebrates. The authors find evidence both for a core response conserved across mammals, and species-specific responses restricted to particular clades.

44. Altincicek B, Gross J, Vilcinskas A: Wounding-mediated gene expression and accelerated viviparous reproduction of the pea aphid Acyrthosiphon pisum. Insect Mol Biol 2008, 17:711-716.

45. Barribeau SM, Parker BJ, Gerardo NM: Exposure to natural pathogens reveals costly aphid response to fungi but not bacteria. Ecol Evol 2014, 4:488-493.

46. Zumaya-Estrada FA, Martínez-Barnetche J, Lavore A, Rivera-Pomar R, Rodríguez MH: Comparative genomics analysis of triatomines reveals common first line and inducible immunity-related genes and the absence of Imd canonical components among hemimetabolous arthropods. Parasit Vectors 2018, 11:48.

- This study uses de novo transcriptome assemblies expand the number of hemimetabolous insects with annotated immune systems, showing that the absence of Imd pathway components is relatively common outside Holometabola.

47. Palmer WJ, Jiggins FM: Comparative Genomics Reveals the Origins and Diversity of Arthropod Immune Systems. Mol Biol Evol 2015, 32:2111-2129.

- This study is one of the first to annotate immune system genes in non-insect arthropods, which provides crucial context for interpreting studies of insect immune system dynamics.

48. Gulia-Nuss M, Nuss AB, Meyer JM, Sonenshine DE, Roe RM, Waterhouse RM, Sattelle DB, de la Fuente J, Ribeiro JM, Megy K, et al.: Genomic insights into the Ixodes scapularis tick vector of Lyme disease. Nat Commun 2016, 7:10507.

49. Rosa RD, Capelli-Peixoto J, Mesquita RD, Kalil SP, Pohl PC, Braz GR, Fogaça AC, Daffre S: Exploring the immune signalling pathway-related genes of the cattle tick Rhipicephalus microplus: From molecular characterization to transcriptional profile upon microbial challenge. Dev Comp Immunol 2016, 59:1-14.

50. Nei M, Gu X, Sitnikova T: Evolution by the birth-and-death process in multigene families of the vertebrate immune system. Proc Natl Acad Sci U S A 1997, 94:7799-7806.

51. Michelmore RW, Meyers BC: Clusters of resistance genes in plants evolve by divergent selection and a birth-and-death process. Genome Res 1998, 8:1113-1130.

52. Al Souhail Q, Hiromasa Y, Rahnamaeian M, Giraldo MC, Takahashi D, Valent B, Vilcinskas A, Kanost $M R$ : Characterization and regulation of expression of an antifungal peptide from hemolymph of an insect, Manduca sexta. Dev Comp Immunol 2016, 61:258-268. 
53. Vizioli J, Bulet P, Hoffmann JA, Kafatos FC, Müller HM, Dimopoulos G: Gambicin: a novel immune responsive antimicrobial peptide from the malaria vector Anopheles gambiae. Proc Natl Acad Sci U S A 2001, 98:12630-12635.

54. Vilcinskas A, Mukherjee $\mathrm{K}$, Vogel $\mathrm{H}$ : Expansion of the antimicrobial peptide repertoire in the invasive ladybird Harmonia axyridis. Proceedings of the Royal Society B: Biological Sciences 2012, 280:20122113-20122113.

55. Vogel $\mathrm{H}$, Schmidtberg $\mathrm{H}$, Vilcinskas $\mathrm{A}$ : Comparative transcriptomics in three ladybird species supports a role for immunity in invasion biology. Dev Comp Immunol 2017, 67:452-456.

- This study, along with ref 54 , demonstrates that expansion of the antimicrobial peptide repertoire is specific to the invasive ladybird $H$. axyridis, and is not found in sister species, suggesting a possible role of enhanced immune competence in $H$. axyridis's success.

56. Gross J, Eben A, Müller I, Wensing A: A well protected intruder: the effective antimicrobial defense of the invasive ladybird Harmonia axyridis. J Chem Ecol 2010, 36:1180-1188.

57. Vilcinskas A, Stoecker K, Schmidtberg H, Rohrich CR, Vogel H: Invasive Harlequin Ladybird Carries Biological Weapons Against Native Competitors. Science 2013, 340:862-863.

58. Gegner T, Otti O, Tragust S, Feldhaar H: Do microsporidia function as "biological weapon" for Harmonia axyridis under natural conditions? Insect Sci 2015, 22:353-359.

59. Altincicek $B$, Vilcinskas $A$ : Analysis of the immune-inducible transcriptome from microbial stress resistant, rat-tailed maggots of the drone fly Eristalis tenax. BMC Genomics 2007, 8:326-312.

60. Scott JG, Warren WC, Beukeboom LW, Bopp D, Clark AG, Giers SD, Hediger M, Jones AK, Kasai S, Leichter CA, et al.: Genome of the house fly, Musca domestica L., a global vector of diseases with adaptations to a septic environment. Genome Biol 2014, 15:466.

61. Sackton TB, Lazzaro BP, Clark AG: Rapid Expansion of Immune-Related Gene Families in the House Fly, Musca domestica. Mol Biol Evol 2017, 34:857-872.

62. Johnston PR, Rolff J: Immune- and wound-dependent differential gene expression in an ancient insect. Dev Comp Immunol 2013, 40:320-324.

63. McTaggart SJ, Hannah T, Bridgett S, Garbutt JS, Kaur G, Boots M: Novel insights into the insect trancriptome response to a natural DNA virus. BMC Genomics 2015, 16:310.

64. Elya C, Lok TC, Spencer QE, McCausland H, Martinez CC, Eisen M: Robust manipulation of the behavior of Drosophila melanogaster by a fungal pathogen in the laboratory. Elife 2018, 7.

65. de Bekker C, Ohm RA, Loreto RG, Sebastian A, Albert I, Merrow M, Brachmann A, Hughes DP: Gene expression during zombie ant biting behavior reflects the complexity underlying fungal parasitic behavioral manipulation. BMC Genomics 2015, 16:620.

66. Shi W, Guo Y, Xu C, Tan S, Miao J, Feng Y, Zhao H, St Leger RJ, Fang W: Unveiling the mechanism by which microsporidian parasites prevent locust swarm behavior. Proc Natl Acad Sci U S A 2014, 
111:1343-1348.

67. Juneja P, Ariani CV, Ho YS, Akorli J, Palmer WJ, Pain A, Jiggins FM: Exome and transcriptome sequencing of Aedes aegypti identifies a locus that confers resistance to Brugia malayi and alters the immune response. PLoS Pathog 2015, 11:e1004765.

68. Tsagmo Ngoune JM, Njiokou F, Loriod B, Kame-Ngasse G, Fernandez-Nunez N, Rioualen C, van Helden J, Geiger A: Transcriptional Profiling of Midguts Prepared from Trypanosoma/T. congolense-Positive Glossina palpalis palpalis Collected from Two Distinct Cameroonian Foci: Coordinated Signatures of the Midguts' Remodeling As T. congolense-Supportive Niches. Front Immunol 2017, 8:876.

69. Sackton TB, Clark AG: Comparative profiling of the transcriptional response to infection in two species of Drosophila by short-read cDNA sequencing. BMC Genomics 2009, 10:259-217.

70. Troha K, Im JH, Revah J, Lazzaro BP, Buchon N: Comparative transcriptomics reveals CrebA as a novel regulator of infection tolerance in D. melanogaster. PLoS Pathog 2018, 14:e1006847.

- This comprehensive study of the transcriptional response to diverse bacterial challenges in $D$. melanogaster is the first to carefully dissect, using RNA-seq, the complexity of both shared and challenge-specific host responses. Furthermore, using functional evidence, they identify a new shared regulator of immune tolerance.

71. Galetto L, Abbà S, Rossi M, Vallino M, Pesando M, Arricau-Bouvery N, Dubrana M-P, Chitarra W, Pegoraro M, Bosco D, et al.: Two Phytoplasmas Elicit Different Responses in the Insect Vector Euscelidius variegatus Kirschbaum. Infect Immun 2018, 86.

72. Etebari K, Hegde S, Saldaña MA, Widen SG, Wood TG, Asgari S, Hughes GL: Global Transcriptome Analysis of Aedes aegypti Mosquitoes in Response to Zika Virus Infection. mSphere 2017, 2.

73. Angleró-Rodríguez YI, MacLeod HJ, Kang S, Carlson JS, Jupatanakul N, Dimopoulos G: Aedes aegypti Molecular Responses to Zika Virus: Modulation of Infection by the Toll and Jak/Stat Immune Pathways and Virus Host Factors. Front Microbiol 2017, 8:2050.

74. Galbraith DA, Yang X, Niño EL, Yi S, Grozinger C: Parallel epigenomic and transcriptomic responses to viral infection in honey bees (Apis mellifera). PLoS Pathog 2015, 11:e1004713.

75. Doublet V, Poeschl Y, Gogol-Döring A, Alaux C, Annoscia D, Aurori C, Barribeau SM, Bedoya-Reina OC, Brown MJF, Bull JC, et al.: Unity in defence: honeybee workers exhibit conserved molecular responses to diverse pathogens. BMC Genomics 2017, 18:207.

- This meta-analysis of previously published RNA-seq and microarray studies in honeybees reveals a core set of shared transcriptional responses to diverse pathogens, and provides an important resource for further work in Hymenoptera. 
76. Schneider DS, Ayres JS: Two ways to survive infection: what resistance and tolerance can teach us about treating infectious diseases. Nat Rev Immunol 2008, 8:889-895.

77. Shrinet J, Srivastava P, Sunil S: Transcriptome analysis of Aedes aegypti in response to monoinfections and co-infections of dengue virus- 2 and chikungunya virus. Biochem Biophys Res Commun 2017, 492:617-623.

78. Bartholomay LC, Waterhouse RM, Mayhew GF, Campbell CL, Michel K, Zou Z, Ramirez JL, Das S, Alvarez K, Arensburger $\mathrm{P}$, et al.: Pathogenomics of Culex quinquefasciatus and Meta-Analysis of Infection Responses to Diverse Pathogens. Science 2010, 330:88-90.

79. Dunn CW, Luo X, Wu Z: Phylogenetic Analysis of Gene Expression. Integr Comp Biol 2013, 53:847856.

80. Rohlfs RV, Nielsen R: Phylogenetic ANOVA: The Expression Variance and Evolution Model for Quantitative Trait Evolution. Syst Biol 2015, 64:695-708.

81. Rohlfs RV, Harrigan P, Nielsen R: Modeling gene expression evolution with an extended OrnsteinUhlenbeck process accounting for within-species variation. Mol Biol Evol 2014, 31:201-211.

- This study is an important paper extending methods of modeling gene expression evolution to account for variation within species. While this method has not been applied to immune system transcriptome studies yet, this study points the way forward for understanding how selection shapes of gene expression using quantitative trait models.

82. Dunn CW, Zapata F, Munro C, Siebert S, Hejnol A: Pairwise comparisons across species are problematic when analyzing functional genomic data. Proceedings of the National Academy of Sciences 2018,

83. Liu Y, Zhou J, White KP: RNA-seq differential expression studies: more sequence or more replication? Bioinformatics 2014, 30:301-304.

84. Schurch NJ, Schofield P, Gierliński M, Cole C, Sherstnev A, Singh V, Wrobel N, Gharbi K, Simpson GG, Owen-Hughes $\mathrm{T}$, et al.: How many biological replicates are needed in an RNA-seq experiment and which differential expression tool should you use? RNA 2016, 22:839-851.

85. Davidson NM, Oshlack A: Corset: enabling differential gene expression analysis for de novo assembled transcriptomes. Genome Biol 2014, 15:410.

86. Robinson GE, Hackett KJ, Purcell-Miramontes M, Brown SJ, Evans JD, Goldsmith MR, Lawson D, Okamuro J, Robertson HM, Schneider DJ: Creating a buzz about insect genomes. Science 2011, 331:1386.

87. Lohman BK, Weber JN, Bolnick DI: Evaluation of TagSeq, a reliable low-cost alternative for RNAseq. Mol Ecol Resour 2016, 16:1315-1321.

88. Misof B, Liu S, Meusemann K, Peters RS, Donath A, Mayer C, Frandsen PB, Ware J, Flouri T, Beutel $R G$, et al.: Phylogenomics resolves the timing and pattern of insect evolution. Science 2014, 
346:763-767. 